\title{
Occupational accidents: a comparative study of construction and manufacturing industries
}

\author{
Shabir Hussain Khahro ${ }^{1, *}$, Tauha Hussain $\mathrm{Ali}^{2}$, Nafees Ahmed Memon ${ }^{2}$ and \\ Zubair Ahmed Memon ${ }^{1}$
}

${ }^{1}$ Department of Engineering Management, Prince Sultan University, Riyadh, Saudi Arabia

${ }^{2}$ Civil Engineering Department, Mahran University of Engineering and Technology, Jamshoro

At present, several developing countries show interest in safety-related issues as a way to reduce occupational accidents in the workplace. The literature depicts that safety culture is a multidimensional idea. Occupational accidents significantly affect human capital, and have a negative impact on productivity and competitiveness of the workers in particular and project in general. There is still a shortage of preventive practices and commitment to satisfactory management for occupational accidents and paucity of safety culture within companies. Construction and manufacturing industries are considered to be risky, having a higher rate of occupational accidents resulting in higher temporary and permanent injuries and fatalities. Both have the highest occupational accident rates recorded throughout the world after the agriculture industry. This study provides a comparative analysis of various kinds of occupational accidents and their causes in both industries in Pakistan. A qualitative study has been carried out on the occupational accidents frequently occurring in both industries. The significant impacts of accidents are also evaluated in this study. The input has been received from professionals working in both industries for a long time. Relative importance weight and quadrant distribution methods is used for information analysis. The study shows that 'fall from elevation, electrocution from defective tools, snakebite, caught between and fall at floor level' are the most common types of occupational accidents in both industries. Poor site condition and equipment are the common causes for occupational accidents. This study helps in developing proactive measures in both industries to prevent occupational accidents. This will result in saving compensation costs as well as working hours, safe and successful completion of projects and maintaining the reputation of the companies.

Keywords: Comparative analysis, construction and manufacturing industries, occupational accidents, proactive measures.

INDUSTRIES play a major role in the socio-economic development of any country. The significance and role of different industries have been confirmed by several studies. The construction and manufacturing industries

\footnotetext{
*For correspondence. (e-mail: shkhahro@psu.edu.sa)
}

contribute significantly to a country's gross domestic product (GDP). Both industries are said to be risky enterprise due to their excessive charge of injuries, fatalities, occupational accidents, people repayment price and loss of working hours ${ }^{1-3}$. Both recorded highest occupational accidents world over compared to other labour-intensive industries. Both industries are closely associated with the field of civil engineering and hence were choose here as a case study. There are numerous factors leading to hazardous situations at the work site, which are difficult to quantify due to various reasons closely associated with the way work activities are performed in both industries; but workers in the construction industry perceive less job safety compared to the manufacturing industry. The reason is the activity type, which includes operating machines, painting, electrocution fittings, etc. and all activities are assigned tasks at different work places ${ }^{4}$. Construction workers perform different tasks at different places, whereas the workers in the manufacturing industry do the same tasks at the same place, and the tasks are mostly controlled $^{4}$. In both sectors, the workplace is chaotic with an incredibly large number of actions that take place, where workers (skilled and semi-skilled) and machines move in a frenzy and focus on the assigned task. In such an environment, accidents can happen.

Many developing countries consider occupational safety and health $(\mathrm{OSH})$ as a priority to prevent accidents and poor health despite work pressures, financial issues and safety culture adaptability problems. Industrial disasters, especially those resulting in multiple fatalities, make global headlines, but the fact is that many people die from their work activities every day, and several fatalities and injuries are unreported and even go unnoticed. Globally, an anticipated 2.3 million people die each year from occupational accidents and work-associated illnesses ${ }^{5}$. Similarly, thousands of workers suffer non-fatal injuries and ailments, as reported by the International Labour Organization (ILO) ${ }^{5}$. Since the restrictions of national information systems differ in several countries, there are no consistent global figures on injuries and work-related diseases. Where available, they are obtained from a variety of sources (social security institutions and insurance, labour inspection, occupational health services and other authorities). Therefore, to address this gap in 
coverage and raise awareness about the problem, estimates of work-related illnesses and occupational accidents are provided in this study based on the available authentic sources.

Every year, occupational accidents and work-related diseases cause over 2.3 million deaths, of which over 350,000 are caused by accidents and about 2 million are work-related diseases. As a result, about 6300 people die every day due to many causes. Workplace accidents kill about 1000 people each day while work-related diseases kill about 5400 people ${ }^{5}$. In November 2015, a four-storey building collapsed in Sunder Industrial Estate, Lahore, Pakistan, killing 46 and wounding more than 100 workers $^{6}$. The work location often changes because each work site evolves as construction proceeds, changing the hazards faced by workers week by week and sometimes even day to day.

In addition to the immeasurable human suffering, deaths and diseases cause major economic losses for businesses and society as a whole, including lost productivity and reduced work capacity. It is estimated that about $4 \%$ of global GDP is lost due to various direct and indirect costs, including compensation, medical expenses, property damage, loss of morale, lower income and training $^{7}$. Prevention and reduction of accidents and injuries in the workplace, not only save workers from pain and suffering, but also help reduce many direct and indirect financial costs.

This study identifies the types of accidents which often take place in construction and manufacturing industries of Pakistan. It also evaluates the impact of each identified accident in both industries, and the direct and indirect causes of occupational accidents. It also provides a platform to take necessary actions accordingly and prevent such accidents in the future. This study will also help the stakeholders of both industries to nurture safety culture in order to present occupational accidents and health problems.

\section{Cement industry}

This industry has the potential for hazards. The workers of this industry are exposed to cement dust that has been demonstrated to have adverse effects on human health. Several studies have reported the effects of cement dust exposure on the respiratory symptom, such as reduction in lung function, high risk of developing chronic obstructive pulmonary disease and reduction in ventilator capaci$\mathrm{ty}^{8}$. Numerous cases of accidents have been reported in the cement industry throughout the world. In 2016, four workers were injured at a cement plant in India. A worker died from a fall at a cement plant in Texas, USA in 2016. In Egypt, four workers died and at least 35 were injured when a scaffold collapsed in a cement plant in 2014. In Malawi, a worker died and three were injured in a cement factory in 2014. In India, one worker died while cleaning the belt of a crusher in a cement plant in 2014. Cement
Australia was fined a large amount as compensation cost for the death of a worker at a cement plant in 2009, who was crushed between two hydraulic rams while working in the factory. In 2013 a worker died at a cement plant in Nigeria when he was hit by falling limestone ${ }^{9}$. In USA, around 2 million workers remain potentially exposed to silica. There is no cure for silicosis, but it can be prevented $^{10}$.

\section{Steel industry}

Historically, the steel industry is known for its accidents. Today, despite the improvement of safety standards and inspections in the metal industry, foundry workers are not free of burns accidents. Molten aluminium is one of the most common pathogens in burns, with an approximate rate of $60 \%$ (ref. 11). Many accidents have been recorded in the steel industry. In 2004, a major industrial accident occurred in Bulgaria's largest iron and steel plant, in which three workers died and 22 more were hospitalized $^{12}$. In 2013, five workers died of suspected oxygen deprivation while working at a steel plant in South Korea. A total of ten workers have died at the same plant since September ${ }^{13}$. Such mishaps are not new, but we do not seem to learn from them. In 2012, a major blast occurred in a steel plant in India, which claimed 16 lives and left many injured. An accident at another steel plant in India claimed six lives and injured over 30 people because of gas leakage from the blast furnace ${ }^{14}$. In USA, 77 fatalities were reported during 2004-2010, while 63, 67 and 64 fatalities were reported in 2011, 2012 and 2013 respectively $^{15}$.

\section{Research methodology}

A detailed literature review has been carried out to identify the different types of occupational accidents which usually occur at construction sites, cement plants and steel plants. The direct and indirect causes leading to occupational accidents were also identified. Structured interviews were conducted with different stakeholders involved in the construction sites, cement plants and steel plants. This helped verify the identified accidents and their causes. Three sets of questionnaire were designed to get the opinion from different stakeholders involved in the construction sites, cement plants and steel plants respectively. In the first phase of the questionnaire, personal details of the respondents were collected. In the second phase, the respondents were requested to rank the frequency of occurrence and impact level of the accidents using a scale ranging from 1 to 4 ((1) very low, (2) low, (3) high and (4) very high). Finally, in the last phase, the respondents were requested to rank the direct and indirect causes of accidents using a scale ranging from 1 to 4 ((1) not significant, (2) slightly significant, (3) significant and (4) very significant). The input of the experts was 
analysed using relative importance weight (RIW) and quadrant distribution (QD) methods.

\section{Data collection and analysis}

For data collection, the construction industry was selected as a whole. On the contrary, in the manufacturing industry two major enterprises were selected, which include the cement and steel industries because of their association with the construction industry. For the cement industry, three cement factories were selected on the basis of their performance and machinery. The first was Lucky Cement Factory which has new machinery and also reported lesser accidents and health problems reported. The second was Thatta Cement Factory which has moderate quality of machinery and slightly more accidents and health problems reported. The third was Power Cement Factory which has old machinery. For the steel industry, Pakistan Steel Mill was selected as a whole because it is a huge plant with thousands of workers. The permission and accessibility problems in the plants were also considered in the final selection process. Data were collected during the period 2017-18. The second and third phase of all questionnaires were analysed using RIW method. The cumulative average mean was calculated using this method. The weights were calculated using eq. (1).

$$
\mathrm{RIW}=\frac{\sum\left(a_{i} x_{i}\right)}{\sum X_{i}},
$$

where $a_{i}$ is the rank of the factor in scale and $x_{i}$ is the variable expressing the frequency of the ranks.

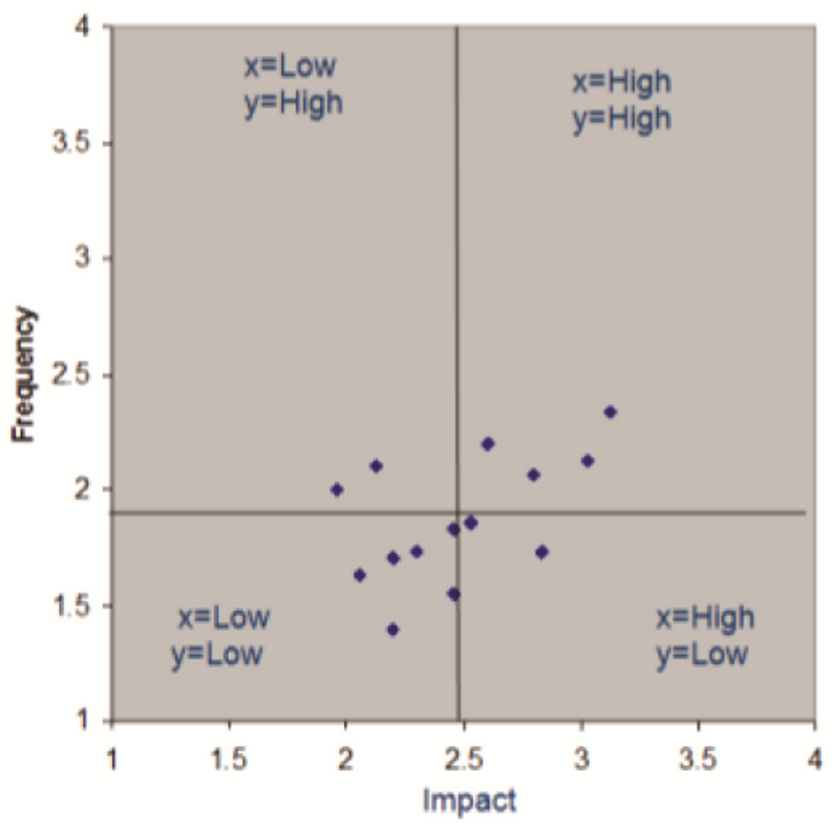

Figure 1. Quadrant distribution method.
The final ranking of the accidents in the second phase was done on the basis of the most frequent and most severe accidents. Hence, QD method was used for final ranking of the accidents (Figure 1).

An accident with higher impact and higher frequency of occurrence was ranked as the most important type, whereas an accident with lower impact and lower frequency of occurrence was ranked as the least important type.

\section{Results and discussion}

More than 300 questionnaires were sent by e-mail and direct contact with different respondents working in both industries for this study. The questionnaires were sent to professionals working in their specific industries at different positions since a long time. The experience of respondents was given priority while distributing the questionnaires. The building and infrastructure projects were selected for construction industry data collection, whereas three cement factories and one large-scale steel factory were selected to collect data for the manufacturing industry. Figure 2 shows the experience of respondents in both industries.

In the first phase of the questionnaire, general data regarding respondents were collected, including respondent name, company name, nature of the project, total experience, etc. In the second phase, the respondents were requested to rank the significance of severity and frequency
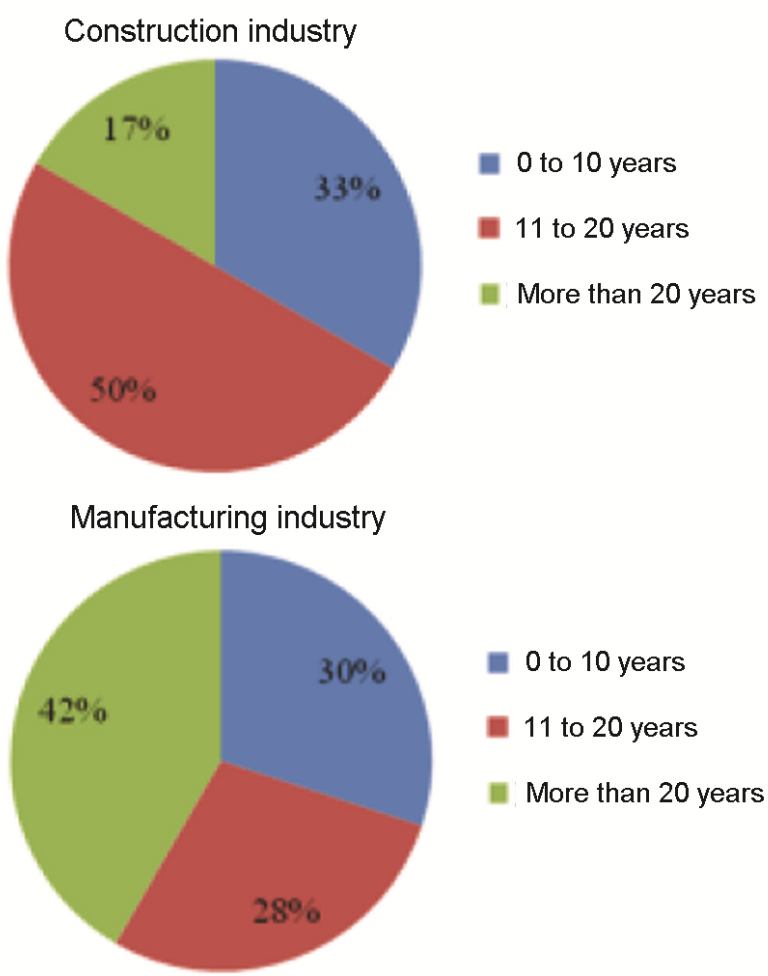

Figure 2. Details of respondents' experience. 
Table 1. List of occupational accidents

\begin{tabular}{|c|c|c|c|c|c|c|}
\hline \multirow[b]{2}{*}{ Type of accident } & \multicolumn{3}{|c|}{ Construction industry } & \multicolumn{3}{|c|}{ Manufacturing industry } \\
\hline & Impact & Frequency & Rank & Impact & Frequency & Rank \\
\hline Electrocution from building power & 3.03 & 2.13 & 2 & 2.28 & 1.46 & 7 \\
\hline Electrocution from faulty tool & 2.80 & 2.06 & 3 & 2.36 & 1.65 & 3 \\
\hline Struck by & 2.60 & 2.20 & 4 & 2.40 & 1.83 & 2 \\
\hline Snakebite & 2.83 & 1.73 & 5 & 2.76 & 1.46 & 5 \\
\hline Caught between & 2.53 & 1.86 & 6 & 2.63 & 1.55 & 6 \\
\hline Slip and fall & 2.13 & 2.10 & 7 & 1.75 & 1.71 & 10 \\
\hline Trip and fall & 1.96 & 2.00 & 8 & 1.53 & 1.43 & 13 \\
\hline Fall at ground level & 2.46 & 1.83 & 9 & 1.93 & 1.60 & 9 \\
\hline Struck against & 2.30 & 1.73 & 10 & 1.98 & 1.61 & 8 \\
\hline Caught on & 2.20 & 1.70 & 11 & 2.21 & 1.61 & 4 \\
\hline Others & 2.20 & 1.40 & 12 & 1.71 & 1.31 & 12 \\
\hline Caught in & 2.06 & 1.63 & 13 & 1.73 & 1.27 & 11 \\
\hline
\end{tabular}

of occurrence of different types of occupational accidents on a Likert scale ranging from 1 to 4 . Using QD method, the final ranking was done for the most common occupational accidents in both industries. Table 1 shows ranking of the most common occupational accidents.

The results show that fall from elevation, electrocution from a faulty tool, snakebite, caught between and fall at ground level are the most common types of occupational accidents in both industries. Interestingly, the results show that accident impact and frequency are the points of focus in both industries. In the construction industry, fall from elevation has a higher level of impact and frequency of occurrence compared to the manufacturing industry. There are many reasons for this, e.g. height levels are fixed in the manufacturing industry, whereas there is no defined working height in the construction industry, resulting in a higher impact. The plants have controlled environment with a higher focus on health and safety regulations, whereas most of the construction sites do not have controlled environment resulting in higher occurrence of fall from elevation. The scenario is the same for electrocution from a faulty tool, caught between and fall to the ground. Snakebite is a common accident with a similar impact in both industries. However, the result shows a higher frequency of occurrence in the construction industry when compared to the manufacturing industry because most plants have closed boundaries and there are greater chances of occurrence of this accident on quarry site in the cement industry. On the other hand, construction sites are located in different regions, including city centres and remote areas. Table 1 also shows the ranking of other types of occupational accidents in both industries. The overall results show that the occupational accidents in the construction industry have higher impact and frequency of occurrence when compared to the manufacturing industry. This highlights the vulnerability of the construction industry in relation to controlled plants of the manufacturing industry.
Table 2. Direct causes of accidents

\begin{tabular}{lccccc}
\hline & \multicolumn{2}{c}{ Construction industry } & & \multicolumn{2}{c}{ Manufacturing industry } \\
\cline { 2 - 3 } \cline { 5 - 6 } Root causes & Weightage (\%) & Rank & & Weightage (\%) & Rank \\
\hline Poor management & 27 & 1 & & 15 & 4 \\
Human element & 22 & 2 & & 32 & 1 \\
Poor work-site & 19 & 3 & & 15.5 & 3 \\
$\quad$ conditions & 18 & 4 & & 23.5 & 2 \\
Nature of work & 14 & 5 & & 14 & 5 \\
Equipment & & & & & \\
\hline
\end{tabular}

In the third phase of the questionnaire, respondents were requested to rank the significance of direct causes leading to different types of occupational accidents on a Likert scale ranging from 1 to 4 . Table 2 shows the synthesized result of direct causes ranking of occupational accidents in both industries.

The results show that poor management is one of the major direct causes of occupational accidents in the construction industry, whereas it is ranked fourth in the manufacturing industry. Poor management includes all managerial mishaps and ignorance regarding safety issues. The human element is ranked as the second direct cause in the construction industry, whereas it is ranked first in the manufacturing industry. Human error is mostly the human negligence towards safety guidelines. Poor worksite condition is ranked third in both industries. Nature of work ranks fourth in the construction industry, whereas it ranks second in the manufacturing industry. Nature of work includes type of industry and type of task that a worker is assigned. Equipment is the fifth direct cause for occupational accidents in both industries. Equipment category includes mostly equipment errors in functionality and partially unavailability of equipment.

In the final phase of the questionnaire, the respondents were requested to rank the significance of indirect causes leading different types of occupational accidents on a 
RESEARCH ARTICLES

Table 3. Indirect causes of accidents

\begin{tabular}{|c|c|c|c|c|}
\hline \multirow[b]{2}{*}{ Indirect causes } & \multicolumn{2}{|c|}{ Construction industry } & \multicolumn{2}{|c|}{ Manufacturing industry } \\
\hline & Mean & Rank & Mean & Rank \\
\hline \multicolumn{5}{|l|}{ Poor management } \\
\hline Shortage in the supply of proper equipment & 3.20 & 1 & 2.18 & 6 \\
\hline Lack of responsibilities & 3.10 & 2 & 2.41 & 2 \\
\hline Tight production/project targets (work pressure) & 2.90 & 3 & 2.38 & 3 \\
\hline Lack of safety meetings & 2.70 & 4 & 2.50 & 1 \\
\hline Productivity bonus & 2.60 & 5 & 1.90 & 10 \\
\hline Lack of orientation training programmes & 2.55 & 6 & 2.36 & 4 \\
\hline Unsafe methods and tasks & 2.50 & 7 & 2.10 & 8 \\
\hline Poor coordination & 2.38 & 8 & 1.78 & 11 \\
\hline Poor training & 2.35 & 9 & 2.11 & 7 \\
\hline Unsafe housekeeping & 2.30 & 10 & 2.28 & 5 \\
\hline Poor supervision & 2.27 & 11 & 1.30 & 13 \\
\hline Poor designing & 2.24 & 12 & 1.46 & 12 \\
\hline High mobility of labour force & 2.20 & 13 & 1.95 & 9 \\
\hline \multicolumn{5}{|l|}{ Human element } \\
\hline Ignorance/negligence regarding safety precautions & 3.10 & 1 & 2.18 & 3 \\
\hline Worker resistance to safety practices & 3.00 & 2 & 2.55 & 1 \\
\hline Lack of responsibilities & 2.70 & 3 & 2.51 & 2 \\
\hline Use of illicit substances & 2.40 & 4 & 1.96 & 5 \\
\hline Caviler attitude & 2.30 & 5 & 2.00 & 4 \\
\hline Not reporting unsafe conditions & 2.27 & 6 & 1.86 & 8 \\
\hline Transit nature of workers & 2.23 & 7 & 1.73 & 9 \\
\hline Improper awareness of machinery & 2.20 & 8 & 1.93 & 7 \\
\hline Personal factors/relationships & 2.15 & 9 & 1.61 & 10 \\
\hline Continuation of work even with fatigue/illness & 2.10 & 10 & 1.95 & 6 \\
\hline \multicolumn{5}{|l|}{ Poor work-site conditions } \\
\hline Unsafe working conditions/environment & 2.9 & 1 & 2.06 & 1 \\
\hline Limited or confined working area & 2.5 & 2 & 1.8 & 2 \\
\hline Rough weather & 2.2 & 3 & 1.65 & 4 \\
\hline Inadequate light provision & 1.8 & 4 & 1.45 & 3 \\
\hline \multicolumn{5}{|l|}{ Nature of work } \\
\hline Strenuous physical task & 2.68 & 1 & 2.16 & 1 \\
\hline Complex and/or unfamiliar nature of work & 2.6 & 2 & 1.86 & 2 \\
\hline \multicolumn{5}{|l|}{ Equipment } \\
\hline Lack of safety equipment/instruments & 3.00 & 1 & 2.15 & 2 \\
\hline Defective equipment and their failure & 2.89 & 2 & 2.30 & 1 \\
\hline Improper use of equipment & 2.70 & 3 & 1.63 & 5 \\
\hline Equipment without safety device & 2.45 & 4 & 1.88 & 4 \\
\hline Poor-quality equipment & 2.40 & 5 & 1.95 & 3 \\
\hline
\end{tabular}

Likert scale ranging from 1 to 4 . Table 3 shows the synthesized result of indirect causes ranking of occupational accidents in both industries due to poor management.

\section{Conclusion and recommendations}

The results show that in the construction industry fall from elevation, electrocution from building power and electrocution from faulty tool are the most significant types of the accident, whereas in the manufacturing industry fall from elevation, struck by and electrocution from faulty tool are the most significant types. All the above accidents are common in both industries and the ranking of a few accidents is the same but it does not mean that both have the same emphasis. The results indicate that the accidents of construction industry have high- er impact and frequency than those of the manufacturing industry, which shows that the construction industry is more hazardous than the manufacturing industry.

This study has identified that in the construction and manufacturing industries of Pakistan, accidents generally occur due to ignorance/negligence regarding safety precautions, worker resistance to safety practices, lack of responsibilities, work pressure, lack of safety meetings, lack of safety equipment/instruments, defective equipment and their failure, unsafe working conditions/ environment, inadequate light provision, limited or confined working area and strenuous physical task. In addition, the short-term and transitory nature of the industry (construction or manufacturing), lack of a controlled working environment and complexity and diversity of the size of the organizations, all have an effect on safety 


\section{RESEARCH ARTICLES}

performance within the industries. To eliminate these causes of accidents, some coping strategies are proposed to improve the safety of workers. No matter how good the strategies are, they will not be implemented if: (1) all the participants do not ascertain a positive attitude towards their own safety and the responsibilities needed to stay safe in a working environment, (2) the government does not take this issue seriously.

Pakistan is a developing country and the construction industry is a neglected sector. Occupational accidents affect the project performance and provide a fertile ground for disputes and claims. It is necessary to bring the attention of the government to this critical issue, so that it can initiate legislation at both the provincial and federal level to reduce accident rates in both industries, but with specific attention to the construction industry. Safety codes or standards (authoritative guides to good practice) should be established, and Pakistan Engineering Council should also implement such standards as a primary component in the registration process of all classes of contractors and consultants. Reasonable fines should be introduced if these rules and regulations are not followed. Further, with respect to the construction industry, no contract should be awarded to those who do not implement the basic safety operating procedure suggested by the competent authority.

Management has a responsibility to educate the workers about company safety plans, procedure for implementation and penalties in case of non-compliance of rules and regulations. The management must organize adequate training programmes for new workers. Workshops for appropriate tools and usage, personal protective equipment and others should be organized to ensure safety. Supervisors have the responsibility to ensure that all their subordinates clearly understand how to perform their work safely and follow safe work practices. Individuals must be held accountable for their performance. Manufacturing industry in Pakistan has certain safety codes and standards because of controlled environment (equipment- oriented rather than human-oriented) and privatization, but there is lack of proper implementation. The strategies proposed in this study will help reduce occupational accidents in both industries. It would bring a change that would save lives and property through the improvement in safety performance in the construction and manufacturing industries of Pakistan.

1. Endroyo, B., Yuwono, B. E., Mardapi, D. and Soenarto, Model of learning/training of occupational safety and health $(\mathrm{OSH})$ based on industry in the construction industry. Procedia Eng., 2015, 125, $83-88$.

2. Fang, Y. C. and Dzeng, R. J., A smartphone-based detection of fall portents for construction workers. Procedia Eng., 2014, 85, $147-156$.

3. Joshi, S. K., Occupational safety and health in Nepal. Int. J. Occup. Saf. Health, 2011, 1(4), 1-2.

4. S. H. K. and Tauha Hussain Ali, F. A. M., Occupational accidents: a perspective of Pakistan construction industry. Mehran Univ. Res. J. Eng. Technol., 2014, 33(3), 341-346.

5. ILO, International Labour Organization, 2014.

6. Hisam, Z., Workplace safety. Dawn, Pakistan, 2016.

7. Loke Yoke Yun et al., Economic cost of work-related injuries and Ill-health in Singapore, 2013.

8. V. K. and Joshi, J. M., Cement dust exposure-related emphysema in a construction worker. Lung India, 2011, 28(4), 294-296.

9. Global Cement Magazine, 2016.

10. American Lungs Association, Lung Health \& Diseases, 2018.

11. Alonso Pena, S., Garcia, A., Gasalla, V. and Campillo, A., Feet sunk in molten aluminium: the burn and its prevention. J. Int. Soc. Burn Inj., 2015, 41(5), 1122-1125.

12. Todorov, T., Major accident at iron and steel plant.

13. L. J. and Wan, L., The Hankyoreh; http://english.hani.co.kr/arti/ english edition/e business/586976.htm

14. Kanchan, S. K., Why are lives so cheap in Indian steel plants. CSA and Down to Earth, 2013.

15. Ibukun Awolusi, E. M., Near-miss reporting to enhance safety in the steel industry. Saf. First, A Publ. Assoc. Iron Steel Technol., 2015, pp. 63-70.

Received 14 February 2018; revised accepted 10 October 2019

doi: $10.18520 / \mathrm{cs} / \mathrm{v} 118 / \mathrm{i} 2 / 243-248$ 